\title{
Determination of Four Volatile N-nitrosamines in the Process of Chinese Preserved Meat
}

\author{
Qingqing Zhu ${ }^{a}$, Junping Wang ${ }^{b}$, Shuangshuang Liu ${ }^{c}$, Yan Zhang ${ }^{d}$ \\ Tianjin University of Science and Technology, Tianjin 300457, China \\ a1031104002@qq.com, bwangjp@tust.edu.cn, '348585254@qq.com, dyzhang@tust.edu.cn
}

Keywords: N-nitrosamines, Chinese preserved meat, GC-MS.

\begin{abstract}
N-nitrosamines (NAs) are harmful substances which have been detected in meat products. In this study, four NAs namely nnitrosodimethylamine (NDMA), n-nituosomethylethylamine (NMEA), n-nitrosodiethylamine (NDEA) and n-nitrosopoperdine (NPIP) was determined in the process of Chinese preserved meat. GC-MS was used to analyze NAs. At each product stage the generation of NDMA is the largest, especially at the baking stage.
\end{abstract}

\section{Introduce}

N-nitrosamines(NAs) are widely present in meat products and considered to be carcinogens and mutagenics, which are formed by the reaction of secondary amines with nitrosating agents[1-2].The nitrosating agents including nitrates and nitrites ,are commonly used in the manufature of Chinese preserved meat. The concentration of NAs in food products depends on the method of cooking, cooking time and temperature, residual and concentration of na precursor and added nitrite concentration [3]. The purpose of this paper was to establish mass spectrometry for determination of NAs in Chinese preserved meat.

\section{Methods}

Chinese preserved meat preparation. Including preparation the row meat, salting, baking, and ripening. First salting temperature $25^{\circ} \mathrm{C}$ for 1 day , baking temparature $65^{\circ} \mathrm{C}$ for 3 days and ripening tempareture $25^{\circ} \mathrm{C}$ for 15 days.One hundred gram meat were randomly taken from each group at following stages: fresh meat, after alting, baking(1d), baking(3d),ripening(5d), ripening (10d), ripening(15d). The minced samples were vacuum-package and stored at $-20^{\circ} \mathrm{C}$. The recipe of the Chinese perserved meat was depicted in table 1.

Table 1 the recipe of the chinese perserved meat

\begin{tabular}{|c|c|c|c|c|c|}
\hline Material & pork & salt & White spirit & soy & Nitrite \\
\hline concentration & $100 \mathrm{~g}$ & $2 \mathrm{~g}$ & $3 \mathrm{~g}$ & $3 \mathrm{~g}$ & $0.015 \mathrm{mg}$ \\
\hline
\end{tabular}

Extraction and purification of volatile NAs .A steam-distillation method was adopted to extract and purify the NAs [4].One hundred gram samples were homogenized in 120ml of ultrapure water with $100 \mathrm{~g}$ of sodium chloride.The homogenate was steamo distilled and approximate $200 \mathrm{ml}$ of the distillate was collected.After addition of $4 \mathrm{ml} 35 \% \mathrm{HCl}$, the distillate was extracted three times with $50 \mathrm{ml}$ of dichloromethane subsequently [5]. The extract was concentrated to $1 \mathrm{ml}$ with rotary evaporators and nitrogen blow the extract to $100 \mu \mathrm{L}$.

Gas chromatography-mass spectrometry analysis. Samples were analyzed by American Varian's Varian 4000 GC-MS (gas chromatography mass spectrometry), the column model DB-5MS $(30 \mathrm{~m} \times 0.25 \mathrm{~mm} \times 0.25 \mu \mathrm{m})$, the gas phase conditions: inlet temperature of $300{ }^{\circ} \mathrm{C}$, Helium 
(purity99.999\%) was used as the carrier gas with a flow rate of $1 \mathrm{~mL} / \mathrm{min}$, the injector temperature was set at $250{ }^{\circ} \mathrm{C}$,split ratio was $5: 1$, temperature program: Initial temperature $50{ }^{\circ} \mathrm{C}$, then $5{ }^{\circ} \mathrm{C} / \mathrm{min}$ increased to $55{ }^{\circ} \mathrm{C}$, then at $15{ }^{\circ} \mathrm{C} / \mathrm{min}$ was raised to $250^{\circ} \mathrm{C}$, maintained $5 \mathrm{~min}$; MS conditions: an ion trap mass separator, the ion source for EI, the ionization energy of $70 \mathrm{eV}$, the ion trap temperature of $220{ }^{\circ} \mathrm{C}$, transfer line temperature was $250{ }^{\circ} \mathrm{C}$, solvent delay for $2.5 \mathrm{~min}$, the scanning range is $43 \sim$ $500 \mathrm{~m} / \mathrm{z}$, retrieval library for NIST 05.

\section{Results and discussion}

Fig. 1 depicts the structure of four targets NAs .the sample of perserved meat were detected byGC-MS and got four kinds of NAs contamination. They are N-nitrosodimethylamine (NDMA), N-nituosomethylethylamine (NMEA), N-nitrosodiethylamine (NDEA) and N-nitrosopoperdine (NPIP) respective. The steam-distillation method can extract and purify them, so they are called volation NAs.<smiles>CN(C)N=O</smiles><smiles>CCN(C)N=O</smiles><smiles>CCN(CC)N=O</smiles><smiles>O=NN1CCCCC1</smiles>

Fig.1 structure of the 4 nitrosanines analyzed in this study

Table 2 The average recovery ,standard deviation and relative standard deviation

\begin{tabular}{cccc} 
Compound & Rec(\%) & SD & RS(\%) \\
\hline NDMA & 77.69 & 0.031 & 2.96 \\
NMEA & 77.65 & 0.027 & 2.32 \\
NDEA & 83.90 & 0.092 & \\
NPIP & 77.48 & 0.059 & 3.29 \\
\hline
\end{tabular}

Experiments conducted to detect NAs contamination in the process of preserved meat. Quantitative date concerning toxic compounds (NDMA, NMEA, NDEA and NPIP) shows in table 2 and analysis of results for the following conclusions. From Fag.1, the experiment revealed the biggest NAs in preserved meat is NDEA and the smallest is NDMA at four stages. There have no NAs been detected raw meat and salting stage meat. NAs are formed in baking stage. The amounts NAs were found at the high meat processing temperature. It seems more probable that NAs were formed when meat were processed at higher temperature. On the first day of the baking, NAs have started to generation and the content of NDEA is biggest and NEMA is minimal. On the third day of the baking, the formation of the sum is the biggest. The generation of NDEA up to $9.492 \mu \mathrm{g} / \mathrm{kg}$ and in the proportion of total content is $74.13 \%$. The maturation stage of NAs content decreased significantly. According to GB9677-1998 the restriction standard regulation of NAs in meat products, the NDMA cannot higher than $3 \mu \mathrm{g} / \mathrm{kg}$ and NDEA is $5 \mu \mathrm{g} / \mathrm{kg}$. The most obvious reduction is NDEA in the process. NPIP is most abundant at 19 days and NPIP perhaps is the most difficult degradation NAs in the meat process. 
Table 3 The level of four NAs in preserved meat

\begin{tabular}{|c|c|c|c|c|c|}
\hline \multirow{2}{*}{ Time(days) } & \multicolumn{4}{|c|}{ Concentration of nas $(\mu \mathrm{g} / \mathrm{kg})$} & \multirow{2}{*}{ Sum of four NAs $(\mu \mathrm{g} / \mathrm{kg})$} \\
\hline & NDMA & NMEA & NDEA & NPIP & \\
\hline 0 & 0 & 0 & 0 & 0 & 0 \\
\hline 1 & 0 & 0 & 0 & 0 & 0 \\
\hline 2 & 0.098 & 1.434 & 3.933 & 1.002 & 6.467 \\
\hline 4 & 0.200 & 0.939 & 9.492 & 2.171 & 12.804 \\
\hline 9 & 0.087 & 0.745 & 5.363 & 2.001 & 8.195 \\
\hline 14 & 0.124 & 0.868 & 2.690 & 2.062 & 5.744 \\
\hline 19 & 0.151 & 0.960 & 0.914 & 1.910 & 3.936 \\
\hline
\end{tabular}

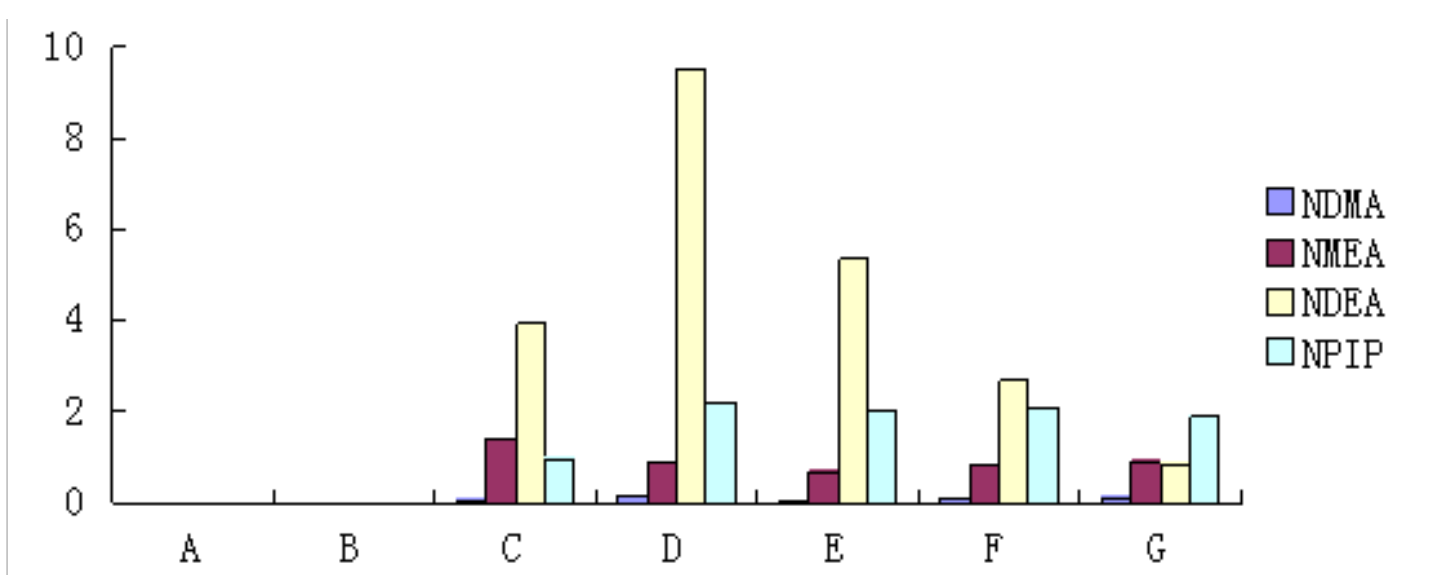

Fig.3 The change of NAs in different processing stage

\section{Conclusions}

GC-MS was used to analyze NAs and 4 kinds of NAs were detected and accurately quantitative. The experiment revealed the biggest NAs is NDEA and the smallest is NDMA at preserved meat process. On the mature stage the four NAs decreased significantly and the least is NDMA.NDMA have a very low level in the process of production and the biggest contest is $0.151 \mu \mathrm{g} / \mathrm{kg}$. The contact of NDMA have an increased trend, the other three NAs reduced gradually. 


\section{Acknowledgements}

This study is supported by the National High-Technology Research and Development Program ("863"Program) of China (Project No.2012AA101604).

\section{References}

[1] S. Yurchenko, U. Mo"lder .The occurrence of volatile N-nitrosamines in Estonian meat products.Food Chemistry[J] ,2007,713-1721

[2] D. Kocaka, M.Z. Ozelb, F. Gogusa.Determination of volatile nitrosamines in grilled lamb and vegetables using comprehensive gas chromatography-Nitrogen chemiluminescence detection. [J].Food Chemistry,2012, 2215-2220

[3]G. Drabik-Markiewicza, B. Dejaegherc, E. De Meya,.Influence of putrescine, cadaverine, spermidine or spermine on the formation of $\mathrm{N}$-nitrosamine in heated cured pork meat[J].Food Chemistry2011,1539-1545

[4]G. Drabik-Markiewicza, B. Dejaegherc, E. De Meya.Evaluation of the influence of proline, hydroxyproline or pyrrolidine in the presence of sodium nitrite on N-nitrosamine formation when heating cured meat.[J].Analytica Chimica Acta,2010,123-130

[5]Fashan Weia,Xinglian Xua,Guanghong Zhoua.Irradiated Chinese Rugao ham: Changes in volatile $\mathrm{N}$-nitrosamine, biogenic amine and residual nitrite during ripening and post-ripening.[J].Meat Science,2009,451-455 